\title{
THERMODYNAMIC ANALYSIS OF ADSORPTION MODELS OF PHENOL IN LIQUID PHASE ON DIFFERENT ACTIVATED CARBONS
}

\author{
P. D. HÚMPOLA ${ }^{1}$ *, H. S. ODETTI ${ }^{1}$, A. E. FERTITTA ${ }^{2}$, J. L. VICENTE ${ }^{2}$ \\ ${ }^{1}$ Departamento de Quimica General e Inorgánica. Facultad de Bioquímica y Ciencias Biológicas. Universidad Nacional del Litoral, Casilla de Correo 242 \\ (3000) Paraje “El Pozo". Santa Fe. Argentina. Teléfono/Fax: +54- 0342-4575212. \\ ${ }^{2}$ Instituto de Investigaciones Fisicoquímicas Teóricas y Aplicadas (INIFTA), (UNLP - CIC - CONICET), \\ Casilla de Correo 16, Sucursal 4 (1900) La Plata, Argentina. \\ (Received: July 5, 2012 - Accepted: November 19, 2012)
}

\begin{abstract}
This paper studies the thermodynamic aspects of the processes of adsorption of phenol from dilute aqueous solutions on different commercial carbons, evaluating how to optimize the removal of this persistent contaminant. Two powdered activated carbons from two different companies were used: Tetrahedron Carbon (Andes Chemistry Lab., Mendoza, Argentina), and Norit (Norit Americas Inc., USA). Both specific surface areas were measured by means of the BET method. The adsorbate was high purity solid phenol (Fluka ${ }^{\circledR} \geq 99.5 \%$ ). Experimental isotherms were determined at $293 \mathrm{~K}, 303 \mathrm{~K}$ and $313 \mathrm{~K}$. The Freundlich and Sips theoretical models were used to fit the experimental data. Freundlich isotherm slightly diverges with the experimental results for higher equilibrium concentrations. Thermodynamic parameters were calculated and correlated with the adsorption behaviours. The values of the thermodynamic parameters obtained indicate an exothermic and spontaneous process for both carbons, and mainly for Norit. This is due to the fact that there might be chemically activated regions on the surface of the Norit carbon, which give rise to combined mechanisms of physisorption and chemisorption.
\end{abstract}

Key Words: adsorption, carbon, phenol, energy.

\section{INTRODUCTION}

Since the 1920s, activated carbon has been used for the conventional treatment of water in order to improve its esthetic quality and to prevent potentially toxic compounds from getting to the consumer ${ }^{1}$. A number of organic compounds are normally found in contaminated water, and among them, phenols and molecules which contain phenolic groups are relatively frequent as contaminants ${ }^{2}$. Activated carbon adsorption has been suggested by the United States Environmental Protection Agency as one of the available technologies to control environmental contamination ${ }^{3}$.

Adsorption of phenolic compounds on activated carbon surfaces is an important technology for water purification. Since adsorption on activated carbon can be affected by the surface properties of the carbons, the chemical composition of the surface groups can be a critical factor in determining the efficiency of the carbons in the removal of a given adsorbate in solution or their duration for use as adsorbents in a water treatment system ${ }^{4}$. Therefore, it is necessary to develop a rational framework for the selection of activated carbons in order to have a more thorough knowledge of the influence of the textural (i.e. pore sizes) and chemical carbon surface characteristics on the adsorption of organic contaminants from aqueous solutions ${ }^{5}$.

It is also worth mentioning that the heats of adsorption or changes in enthalpies of adsorption $\left(\Delta \mathrm{H}^{\circ}\right)$ have been considered as indicators of the energetic heterogeneity of an adsorbent in adsorption ${ }^{6}$, which depends on the distribution of micropores and mesopores of different shapes and sizes as well as on the distribution of adsorption sites of different chemical nature (polarity) within the pores.

The difference between physisorption and chemisorption lies in the magnitude of the enthalpy and Gibbs free energy changes. Generally, the $\Delta \mathrm{G}^{\circ}$ value is in the range of 0 to $-20 \mathrm{~kJ} \cdot \mathrm{mol}^{-1}$ and -80 to $-400 \mathrm{~kJ}^{-\mathrm{mol}^{-1}}$ for physical and chemical adsorptions, respectively. The magnitude of the $\Delta \mathrm{H}^{\circ}$ value lies in the range of -2.1 to -20.9 and -80 to $-200 \mathrm{~kJ}^{-\mathrm{mol}^{-1}}$ for physical and chemical adsorptions, respectively. Positive $\Delta \mathrm{S}^{\circ}$ value suggests the organization of the adsorbate at the solid/solution interface becomes more random, while negative value suggests the opposite fact. It is also supposed that the change of $\Delta \mathrm{S}$ 。 value is related to the displacement of the adsorbed water molecules by the adsorbate ${ }^{7}$. Heat is always released in the process, thus adsorption enthalpy is negative, which means that there will be a decrease of entropy in adsorption. This is due to the fact that a molecule in its gaseous state or in solution has more freedom of movement than one that is bonded to the surface ${ }^{8,9,10}$.

The aim of this paper is to study the adsorption of phenol from dilute aqueous solutions on different commercial carbons, evaluating how to optimize the removal of this persistent contaminant, and correlating the adsorption behaviours to the thermodynamic analysis.

\section{EXPERIMENTAL}

\subsection{Characterization of Adsorbents}

Equilibrium isotherms for the adsorption of nitrogen $\left(\mathrm{N}_{2}\right)$ in the gas phase were measured at $77.4 \mathrm{~K}^{11}$. This was done for two commercially available active carbon samples which were obtained from the Tetrahedron Carbon (Andes Chemistry Lab., Mendoza, Argentina), and Norit (Norit Americas Inc., USA) companies. Tables 1 and 2 present information about these materials obtained from BET standard analysis and the characterization of the microporosity from Dubinin-Astakhov (DA). At relative lower pressures, i.e., $x=p / p_{0} \leq 0.01$, the micropore filling process takes place. The DA equation has been used to describe the volume filling of micropores and the energetic heterogeneity of solids ${ }^{12}$. DA proposed to relate the volume $V$ occupied by the adsorbate with the differential molar work of adsorption, $A=R T \log (1 / x)$, via the following equation:

$$
F_{D A}(x)=C_{1,1} \exp \left\{-\left(\frac{R T \ln (1 / x)}{C_{1,2}}\right)^{C_{1,3}}\right\}
$$

According to the Polanyi-Dubinin theories, $C_{u}$ is the micropore volume, $\theta=V / C_{l, l}, R T \ln (1 / x)$ is the differential molar work of adsorption; $C_{l, 2}=\beta E_{0}$, where $E_{0}$ is the characteristic energy, $\beta$ is the function of the adsorbate, and $C_{1,3}$, describes the surface heterogeneity. For simplicity, if Eq. (1) is written $C_{1,3}=$ 2 , the DA equation reduces to the Dubinin-Radushkevich (DR) equation, first proposed to describe solids with low degree of burn-off. The exponent values proposed are $C_{l, 3}>4$ for zeolites, $C_{l, 3}=2-3$ for homogeneous carbons, and $C_{l, 3}$ $<2$ for heterogeneous active carbons.

The DA equation corresponds to the choice of arbitrary values in the Weibull distribution function. With this additional parameter in the adsorption isotherm equation, the DA equation provides flexibility in the description of adsorption data of many microporous solids ranging from a narrow to a wide micropore size distribution ${ }^{13}$.

The gas phase isotherms were volumetrically determined employing Pyrex conventional equipment. The corresponding values for $\mathrm{N}_{2}$ at $77.4 \mathrm{~K}$ are shown in Figures 1-2. Pressures were determined using absolute capacitance manometers, MKS - Baratron $122 \mathrm{AA}-00010 \mathrm{AB}$, with $1.0^{\prime} 10^{-3}$ Torr maximum error. Work temperatures were thermostatically controlled. Temperature was measured with a digital thermometer, Altronix, with a Pt-100 (DIN) sensor head, previously calibrated against an oxygen vapour pressure thermometer with $0.1 \mathrm{~K}$ precision ${ }^{14}$. Gases, provided by Matheson Gas Products, were employed without any previous treatment and they were of high purity, greater than $99 \%$. 
2.2 Adsorption Measurements

The adsorbate was high purity solid phenol (Fluka ${ }^{\circledR} \geq 99.5 \%$ ). Experimental isotherms from dilute aqueous solutions were determined twice in order to assess their reproducibility, at a constant temperature of $293 \mathrm{~K}, 303$ $\mathrm{K}$ and $313 \mathrm{~K}$ with periodic manual agitation. The initial phenol concentrations ranged from 0.1 to $0.6 \mathrm{~mol} . \mathrm{L}^{-1}$ and the mass of carbon was in the range of $0.3000 \mathrm{~g} \pm 0.0005 \mathrm{~g}$. Initial and equilibrium concentrations of phenol were determined by molecular absorption spectrophotometry at $272.2 \mathrm{~nm}$ using the UV-Visible CECIL CE 3021 SERIES 3000 spectrophotometer ${ }^{15}$. These data were used to calculate the quantity adsorbed per unit mass of the adsorbent.

\subsection{Adsorption Isotherms}

Data were fitted by using Freundlich and Sips theoretical models and SigmaPlot V. 10.0 software. Their mathematical representations are given below:

\section{Freundlich Isotherm}

$$
n=K_{F} \cdot C_{e q}^{1 / n F}
$$

where $n$ is the adsorbed amount at equilibrium(mol. $\left.\mathrm{g}^{-1}\right), C_{e q}$ the adsorbate equilibrium concentration $\left(\mathrm{mol}^{-1} \mathrm{~L}^{-1}\right), K_{F}$ is a constant indicative of the relative adsorption capacity of the adsorbent $\left(\mathrm{mol}^{1-(1 / n)} \mathrm{L}^{1 / n} \mathrm{~g}^{-1}\right)$ and $n_{F}$ is a constant indicative of the intensity of the adsorption. The Freundlich expression is an exponential equation and therefore, assumes that as the adsorbate concentration increases, the concentration of adsorbate on the adsorbent surface also increases. The magnitude of the exponent $n_{F}$ gives an indication on the favourability of adsorption. It is generally stated that values of $n_{F}$ in the range 2-10 represent good, 1-2 moderately difficult, and less than 1 poor adsorption characteristics. Freundlich isotherm slightly diverges with the experimental results for higher equilibrium concentrations $\mathbf{s}^{16,17,18}$

\section{Sips Isotherm}

Recognizing the problem of the continuing increase in the adsorbed amount with an increase in concentration in the Freundlich equation, Sips proposed an equation similar in form to the Freundlich equation, but it has a finite limit when the concentration is sufficiently high. The Sips isotherm equation is sometimes called the Langmuir-Freundlich equation in the literature because it has the combined form of Langmuir and Freundlich equations.

$$
n=n_{m L F}\left(K_{L F} C_{e q}\right)^{1 / n L F} /\left[1+\left(K_{L F} C_{e q}\right)^{1 / n L F}\right.
$$

where $n$ is the adsorbed amount at equilibrium $\left(\right.$ mol. $\left.^{-1}\right), n_{m L F}$ the Langmuir-Freundlich maximum adsorption capacity $\left(\mathrm{mol} . \mathrm{g}^{-1}\right),{ }^{m L F} C_{e q}$ the adsorbate equilibrium concentration $\left(\mathrm{mol} . \mathrm{L}^{-1}\right), K_{L F}$ the equilibrium constant for a heterogeneous solid, and $n_{L F}$ is the heterogeneity parameter, lying between 0 and 1 . In form this equation resembles that of Langmuir equation. The difference between this equation and the Langmuir equation is the additional parameter " $n_{L F}$ " in the Sips equation. If this parameter $n_{L F}$ is unity, the Langmuir equation can be applicable for ideal surfaces. Hence the parameter $n_{L F}$ could be regarded as the parameter characterizing the system heterogeneity. The system heterogeneity could stem from the solid or the adsorbate or a combination of both. The parameter $n_{L F}$ is usually greater than unity, and therefore the larger this parameter the more heterogeneous the system $^{19,20}$. At low adsorbate concentrations, it reduces to Freundlich isotherm; while at high concentrations, it predicts a monolayer adsorption capacity characteristic of the Langmuir isotherm ${ }^{21}$.

\subsection{Adsorption Thermodynamics}

The adsorption thermodynamics were studied to gain an insight into the adsorption behaviours. Parameters including Gibbs free energy change $\left(\Delta \mathrm{G}^{\circ}\right)$, enthalpy change $\left(\Delta \mathrm{H}^{\circ}\right)$ and entropy change $\left(\Delta \mathrm{S}^{\circ}\right)^{22}$ are calculated according to the following thermodynamic equations:

$$
\begin{aligned}
& \Delta G=-R T \ln K \\
& \ln K=(\Delta S / R)-(\Delta H / R T)
\end{aligned}
$$

where $\mathrm{K}\left(\mathrm{L} \cdot \mathrm{mol}^{-1}\right)$ is from Freundlich and Sips equations, R is the gas constant $\left(8.314 \mathrm{~J}^{-\mathrm{mol}^{-1}} \mathrm{~K}^{-1}\right)$ and $\mathrm{T}$ is the temperature in Kelvin. In the application of Eq. (5), the values of $\ln \mathrm{K}$ are plotted against $1 / \mathrm{T}$, the $\Delta \mathrm{H}^{\circ}$ and $\Delta \mathrm{S} \circ$ values are calculated from the slope and intercept of the plot.

\section{RESULTS AND DISCUSSION}

Table 1. Activated Carbon Characterization.

\begin{tabular}{|c|c|c|}
\hline & $\begin{array}{c}\text { Specific surface } \\
\text { area }\left[\mathrm{m}^{2} \cdot \mathrm{g}^{-1}\right]\end{array}$ & $\begin{array}{c}\text { Monolayer } \\
\text { volume }\left[\mathrm{mL} \cdot \mathrm{g}^{-1}\right]\end{array}$ \\
\hline TETRAHEDRON & 545.32 & 148.6 \\
\hline NORIT & 680.23 & 154.3 \\
\hline
\end{tabular}

Table 2. $\boldsymbol{D} \boldsymbol{A}$ Parameter Values for a Low Pressure Range $\left(\mathrm{N}_{2}\right.$ at $\left.77.4 \mathrm{~K}\right)$

\begin{tabular}{|c|c|c|c|}
\hline & $\mathrm{C}_{1,1}\left[\mathrm{~mL} \cdot \mathrm{g}^{-1}\right]$ & $\mathrm{E}_{0}\left[\mathrm{~kJ} \cdot \mathrm{mol}^{-1}\right]$ & $\mathrm{C}_{1,3}$ \\
\hline TETRAHEDRON & 140 & 23.8 & 3.0 \\
\hline NORIT & 204 & 21.8 & 1.9 \\
\hline
\end{tabular}

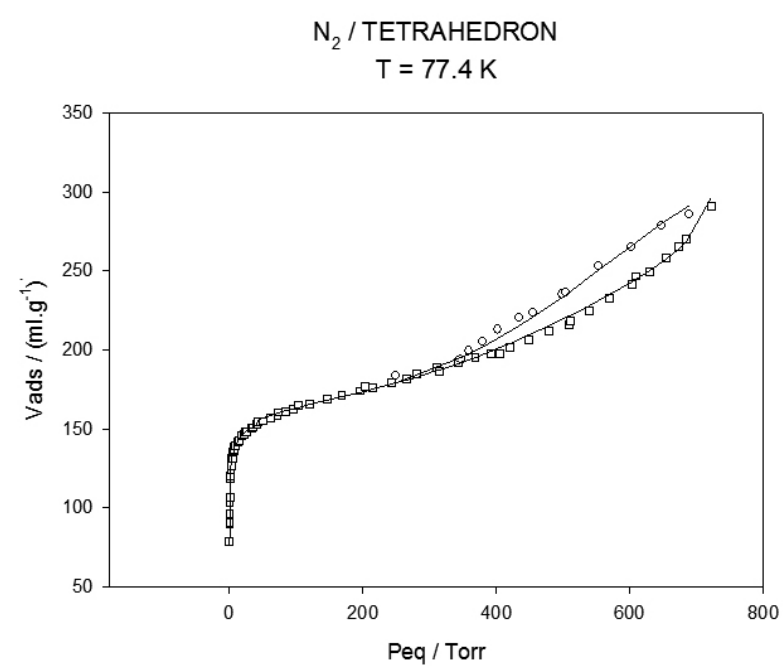

Fig. 1: Isotherms of $\mathrm{N}_{2}$ adsorption - desorption on Tetrahedron Carbon at $77.4 \mathrm{~K}$.

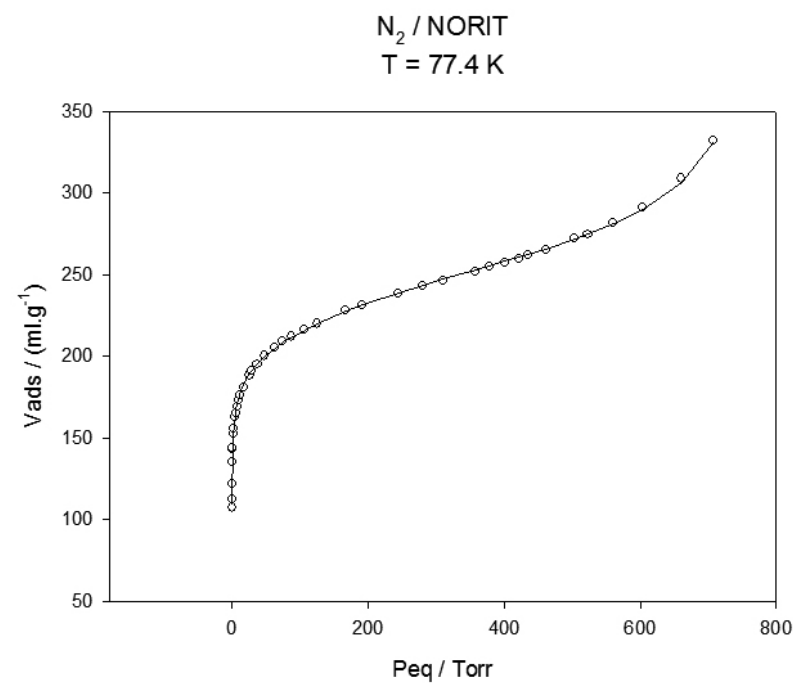

Fig. 2: Isotherms of $\mathrm{N}_{2}$ adsorption - desorption on Norit Carbon at 77.4 K. 


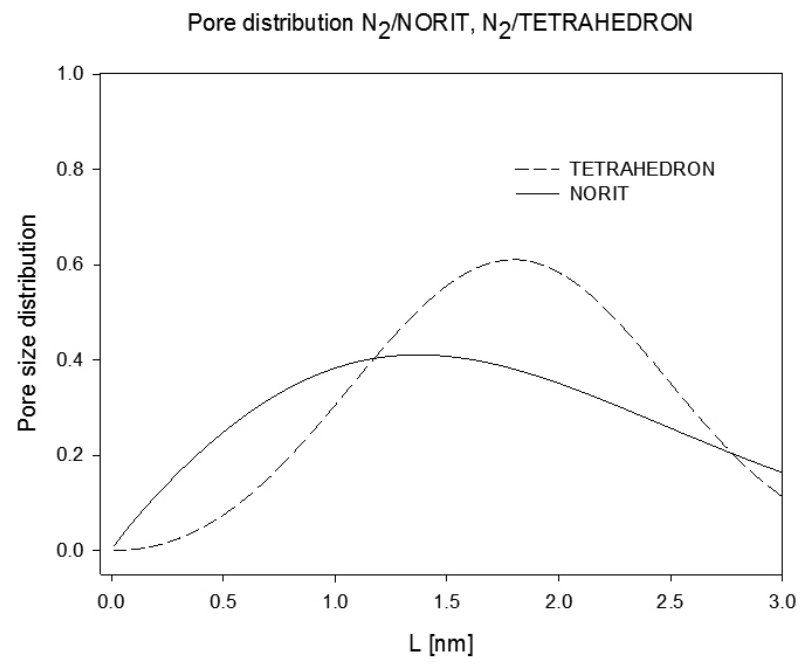

Fig. 3: Comparison of pore size distribution of Norit (full line) and Tetrahedron (dashed line) carbons from the isotherms of $\mathrm{N}_{2}$ adsorption at 77.4 K.

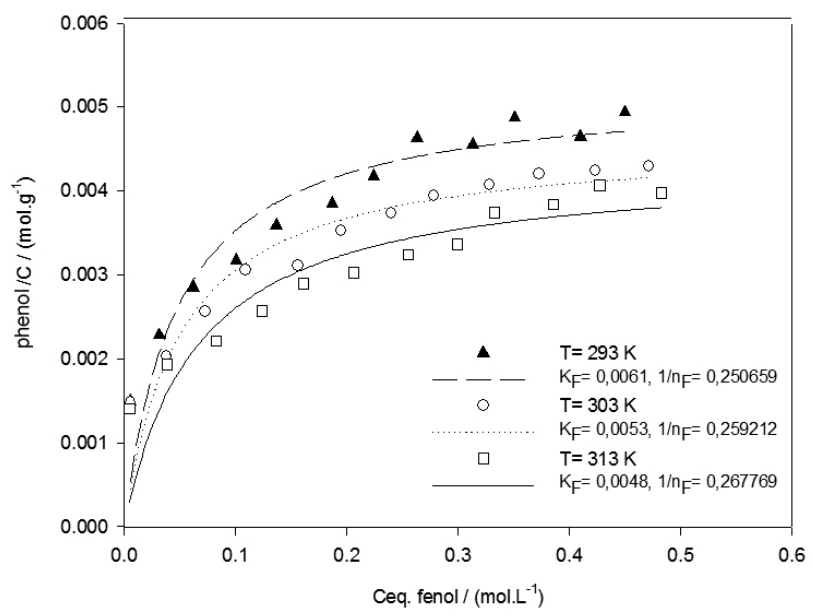

Fig. 4: Adsorption Isotherm for Tetrahedron Carbon. Freundlich $\eta=$ $\mathrm{K}_{\mathrm{F}} \cdot \mathrm{C}_{\mathrm{eq}}^{1 / \mathrm{nF}}$

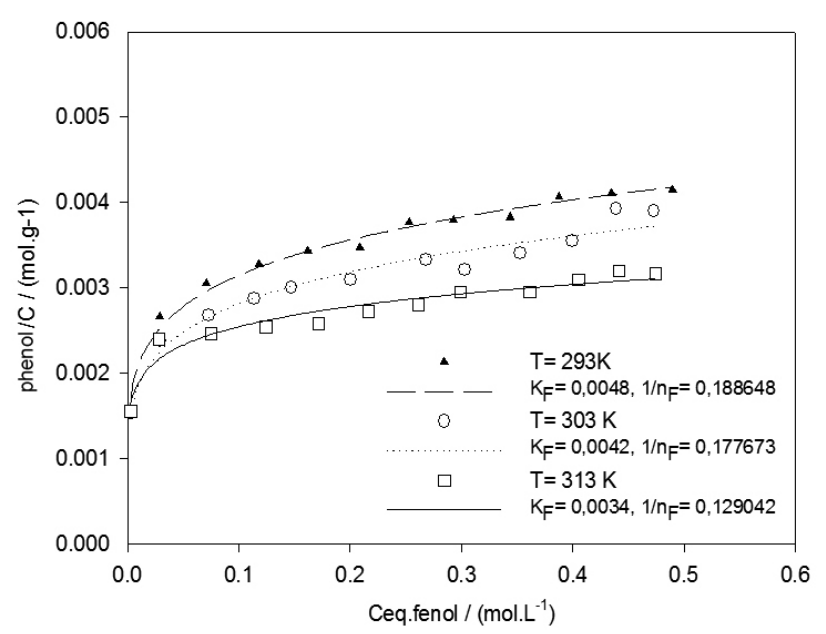

Fig. 5: Adsorption Isotherm for Norit Carbon. Freundlich $\eta=K_{\mathrm{F}} \cdot \mathrm{C}_{\mathrm{eq}}{ }^{1 / \mathrm{FF}}$

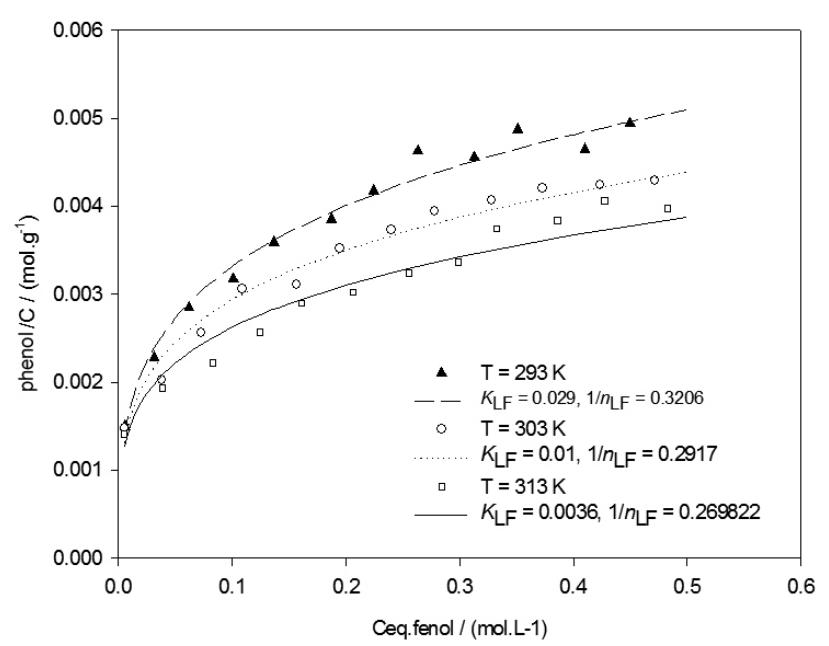

Fig. 6: Adsorption Isotherm for Tetrahedron Carbon. Sips $\eta=n_{m L F}\left(K_{L F}\right.$

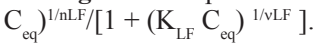

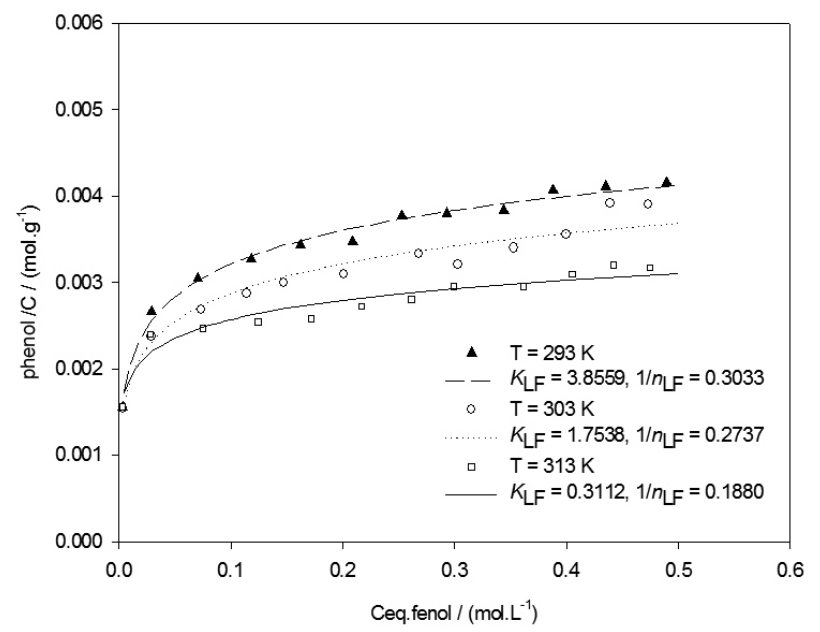

Fig. 7: Adsorption Isotherm for Norit Carbon. Sips $\eta=\eta_{m L F}\left(K_{L F} C_{e q}\right)^{1}$ $\mathrm{nLF} /\left[1+\left(\mathrm{K}_{\mathrm{LF}} \mathrm{C}_{\mathrm{eq}}\right)^{1 / \mathrm{LLF}}\right]$.

Table 3. Adsorption Energies Obtained from Freundlich Model.

\begin{tabular}{|c|c|c|}
\hline \multicolumn{3}{|c|}{ FREUNDLICH $n=K_{F} C_{e q .}{ }^{1 / n F}$} \\
\hline & Tetrahedron Carbon & Norit Carbon \\
\hline$\Delta \mathrm{H}\left(\mathrm{KJ}^{\mathrm{m}} \mathrm{mol}^{-1}\right)$ & -9.16 & -13.11 \\
\hline$\Delta \mathrm{S}\left(\mathrm{KJ}^{-1} \mathrm{~mol}^{-1} \cdot \mathrm{K}^{-1}\right)$ & 0.075 & 0.083 \\
\hline$\Delta \mathrm{G}\left(\mathrm{KJ}_{\mathrm{mol}}^{-1}\right) 293 \mathrm{~K}$ & -31.75 & -35.38 \\
\hline$\Delta \mathrm{G}\left(\mathrm{KJ}^{-1} \mathrm{~mol}^{-1}\right) 303 \mathrm{~K}$ & -32.32 & -36.21 \\
\hline$\Delta \mathrm{G}\left(\mathrm{KJ} \cdot \mathrm{mol}^{-1}\right) 313 \mathrm{~K}$ & -33.10 & -37.03 \\
\hline
\end{tabular}

Table 4. Adsorption Energies Obtained from Sips Model.

\begin{tabular}{|c|c|c|}
\hline \multicolumn{3}{|c|}{$\operatorname{SIPS}\left(n=n_{m L F}\left(K_{L F} C_{e q}\right)^{n L F} / 1+\left(K_{L F} C_{e q}\right)^{n L F}\right)$} \\
\hline & Tetrahedron Carbon & Norit Carbon \\
\hline$\Delta \mathrm{H}\left(\mathrm{KJ}^{\prime} \mathrm{mol}^{-1}\right)$ & $-78,87$ & -95.53 \\
\hline$\Delta \mathrm{S}\left(\mathrm{KJ}_{\mathrm{mol}}^{-1} \cdot \mathrm{K}^{-1}\right)$ & 0.30 & 0.31 \\
\hline$\Delta \mathrm{G}\left(\mathrm{KJ}_{\mathrm{mol}}{ }^{-1}\right) 293 \mathrm{~K}$ & -166.81 & -187.42 \\
\hline$\Delta \mathrm{G}\left(\mathrm{KJ}^{-1} \mathrm{~mol}^{-1}\right) 303 \mathrm{~K}$ & -169.80 & -190.56 \\
\hline$\Delta \mathrm{G}\left(\mathrm{KJ}_{\mathrm{mol}}^{-1}\right) 313 \mathrm{~K}$ & -172.80 & -193.69 \\
\hline
\end{tabular}


Data for specific surface areas (table 1 and figures 1 and 2) show that Norit carbon has a higher surface area value than Tetrahedron, which indicates that the former will have a higher adsorption capacity for the same amount measured in equilibrium.

Figures 1 and 2, which show the $\mathrm{N}_{2}$ isotherms at $77.4 \mathrm{~K}$, present clear differences in the two carbons. Norit isotherm is reversible while the hysteresis loop of Tetrahedron (Figure 1) reflects capillary condensation.

From Table 2, according to the DA fit (Figures 1 and 2), we note that $\mathrm{N}_{2}$ adsorption at $77.4 \mathrm{~K}$ shows that $E_{0}$ for Tetrahedron $\left(23.8 \mathrm{~kJ} \mathrm{~mol}^{-1}\right)$ is greater than for Norit $\left(21.8 \mathrm{~kJ} \mathrm{~mol}^{-1}\right)$, whereas $C_{1}$ is in the inverse order, Norit (204 $\left.\mathrm{mL} \cdot \mathrm{g}^{-1}\right)$ and Tetrahedron $\left(140 \mathrm{~mL} \cdot \mathrm{g}^{-1}\right)$. The parameter $C_{1,3}$ is different for both carbons: 1.0 for Norit and 3 for Tetrahedron. As for their microporosity, both carbons present similar average diameters: $\mathrm{L}=0.9 \mathrm{~nm}$ for Tetrahedron and $\mathrm{L}$ $=1.0 \mathrm{~nm}$ for Norit.

Thus, in agreement with other authors, it is suggested that the Freundlich model is only valid at low equilibrium concentrations of the adsorbate in solution, as the Freundlich isotherm slightly diverges with the experimental results for higher equilibrium concentrations. Sips circumvents the limitation of the rising adsorbate concentration, associated with the Freundlich isotherm model. As to the Sips model, it can also be observed that the $\mathrm{K}_{\mathrm{LF}}$ parameter presents higher values for the Norit carbon -which corresponds to its higher surface area value- for the whole range of equilibrium concentrations of phenol. $n_{F}$ values are in the range of 2-10 and $n_{L F}$ are greater than unity. For the three temperature values $(293,303$ and $313 \mathrm{~K}$ ), adsorption decreases with increasing temperature on both carbons (figures 4, 5, 6 and 7). This finding correlates with the evolution of the parameters $K_{F}$ and $K_{L F}$ : as the temperature increases, these values decrease, thus indicating lower adsorption capacity of both carbons. Negative $\Delta \mathrm{G}^{\circ}$ values are obtained in all cases, revealing the spontaneous nature of these adsorptions. The $\Delta \mathrm{H}^{\circ}$ values are negative, demonstrating the exothermic nature of these adsorptions, which is in agreement with the experimental observations (tables 3 and 4 ).

There are also important differences in the thermodynamic parameters as determined by both fitting models. The greater values in the measurement of $\Delta \mathrm{H}^{\circ}$ obtained with Sips indicate that this model is more appropriate to interpret phenol adsorption. This process seems to occur by physisorption and chemisorption due to certain heterogeneity on the surface associated with the surface groups. This tendency, more marked in the Norit carbon, can be correlated with the behaviour observed for this carbon in the DA heterogeneity parameter.

\section{CONCLUSIONS}

Adsorption isotherms are important to describe the interaction between the adsorbates and the activated carbon and are crucial to optimize the use of the latter as an adsorbent. The fact that the Sips model gave a better fit indicates that this is a useful approach to the heterogeneity of the surface and to study the behaviour of the phenol on the surface for the whole range of equilibrium concentrations suggested. Although the Freundlich model is appropriate to describe the region of low concentrations, it is not valid for higher concentrations, where the interactions of the phenol molecules in the solution are likely to have a more important role, thus reducing the affinity of phenol towards the surface.

Current results in our laboratory for adsorption of phenolic compounds from aqueous solutions using the two above mentioned activated carbons, have shown different behaviours, which can be attributed to micropore filling, and meso and macropore adsorption. In these cases, the presence of surface chemical groups will certainly increase the degree of complexity and heterogeneity, which is also coherent with the hereby presented description (the process of micropore filling favours carbon Norit over Thetrahedron). The values of the thermodynamic parameters obtained indicate an exothermic and spontaneous process for both carbons, and mainly for Norit. This is due to the fact that there might be chemically activated regions on the surface of the Norit carbon, which give rise to combined mechanisms of physisorption and chemisorption.

\section{REFERENCES}

1. Newcombe, G. in Adsorption by Carbon. Adsorption from Aqueous Solutions: Water Purification. Edited by Bottani-Tascón. Elsevier Amsterdam, 2008.

2. Nevskaia D.M., Castillejos-López E., Guerrero-Ruiz A., Muñoz V, Carbon, 42, 653, (2004).

3. Moreno-Castilla, C., Carbon, 42, 83, (2004).

4. MacDonald JAF., Evans MJB., Carbon, 40, 703, (2002).
5. Lei L., Quinlivan PA., Knappe Detlef RU., Carbon, 40, 2085, (2002).

6. Hernández-Huesca R, Aguilar-Armenta G., Journal of the Mexican Chemical Society, 46, 109, (2002).

7. Qing-Song, L.; Tong, Z.; Peng, W.; Ji-Ping, J.; Nan, L., Chem. Eng. J., 157, 348, (2010).

8. Khan AR, Ataullah R, Al-Haddad A., J. Colloid Interface Sci., 194, 154 , (1997).

9. Singh KP., Malik A, Sinha S, Ojha P., J. Hazard. Mater., 150, 626, (2008).

10. Srihari V, Das A., Desalination, 225, 220, (2008).

11. Antilén, M; Förster, J.; Del Cofetto, Sylvie; Rodier Elizabeth, Fudym Oliver; Venezia, Anna M.; Deganello G and Escudey, M., J. Chil. Chem. Soc., 49, 313, (2004).

12. Gil, A.; Grange, P, Colloids Surf. A, 113, 39, (1996).

13. Rychlicki, G.; Terzyk, A.P.; Lukaszewicz, J.P., Colloids Surf. A. 96, 105, (1995).

14. Albesa AG, Llanos JL, Vicente JL., Langmuir, 24, 3836, (2008).

15. Siva Kumar, N.; Min K. J., Chil. Chem. Soc., 56, 539, (2011).

16. Hamdaoui, O.; Naffrechoux, E., J. Hazard. Mater., 147, 381, (2007).

17. Mourao, P.A.M.; Carrott, P.J.M.; Ribeiro Carrott, M.M.L., Carbon, 44, 2422, (2006).

18. Chung-Hai, Y., J. Colloid Interface Sci., 208, 379, (1998).

19. Hamdaoui, O.; Naffrechoux, E.; J., J. Hazard. Mater., 147, 401, (2007).

20. Duong, D. Do. in Adsorption Analysis: Equilibria and Kinetics. Practical Approaches of Pure Component Adsorption Equilibria. Imperial College Press, 1998

21. Foo, K.Y.; Hameed, B.H., Chem. Eng. J., 156, 2, (2010).

22. Kanwal, F: Rehman, R.; Mahumud, T; Anwar, J.; Ilyas, R., J. Chil. Chem. Soc, 57, 1058, (2012) 